Supporting information for:

Particle Size Effects on the Order-Disorder Phase Transition in $\left[\left(\mathrm{CH}_{3}\right)_{2} \mathrm{NH}_{2}\right] \mathrm{Mg}(\mathrm{HCOO})_{3}$

Steven A. LoCicero, † Carolyn M. Averback, † Ulyana Shumnyk, † Eun Sang Choi,§ Daniel R. Talham* ${ }^{*} \dagger$

†Department of Chemistry, University of Florida, Gainesville, FL 32611-7200, United States

§National High Magnetic Field Lab, Tallahassee, FL 32310 United States

Contents:

1. Particle Characterization

Figure S1. Histograms of 1-2.3 $\mu \mathrm{m}, 1-0.8 \mu \mathrm{m}, 1-0.4 \mu \mathrm{m}$, and 1-0.2 $\mu \mathrm{m}$.

Figure S2. TEM images of 1-2.3 $\mu \mathrm{m}$ and 1-0.4 $\mu \mathrm{m}$.

Figure S3. PXRD patterns of 1-B, 1-2.3 $\mu \mathrm{m}, 1-0.8 \mu \mathrm{m}, 1-0.4 \mu \mathrm{m}$, and 1-0.2 $\mu \mathrm{m}$.

Figure S4. FTIR of 1-B after consecutive $\mathrm{KBr}$ pellet grinding.

Figure S5. TGA curves of 1-B, 1-2.3 $\mu \mathrm{m}, 1-0.8 \mu \mathrm{m}, 1-0.4 \mu \mathrm{m}$, and 1-0.2 $\mu \mathrm{m}$.

Figure S6. Inverse temperature dependence of the relaxation time of the samples 1-B, 1-0.8 $\mu \mathrm{m}$, and 1$0.2 \mu \mathrm{m}$.

Figure S7. Polarization of 1-B.

Figure S8. Pyroelectric current measurements of 1-B, 1-0.8 $\mu \mathrm{m}$, and 1-0.2 $\mu \mathrm{m}$.

Table $S 1 . T_{\mathrm{c}}$ and thermal hysteresis of 1-2.3 $\mu \mathrm{m}$, and 1-0.4 $\mu \mathrm{m}$.

Figure S9. DSC curves of 1-B, and 1-2.3 $\mu \mathrm{m}$, and 1-0.4 $\mu \mathrm{m}$.

Figure S10. DSC of 1-B, 1-2.3 $\mu \mathrm{m}$, and 1-0.4 $\mu \mathrm{m}$.

Table S2. PXRD peak assignments for 1-2.3 $\mu \mathrm{m}$ and 1-0.4 $\mu \mathrm{m}$.

2. SI References 


\section{Particle Characterization:}
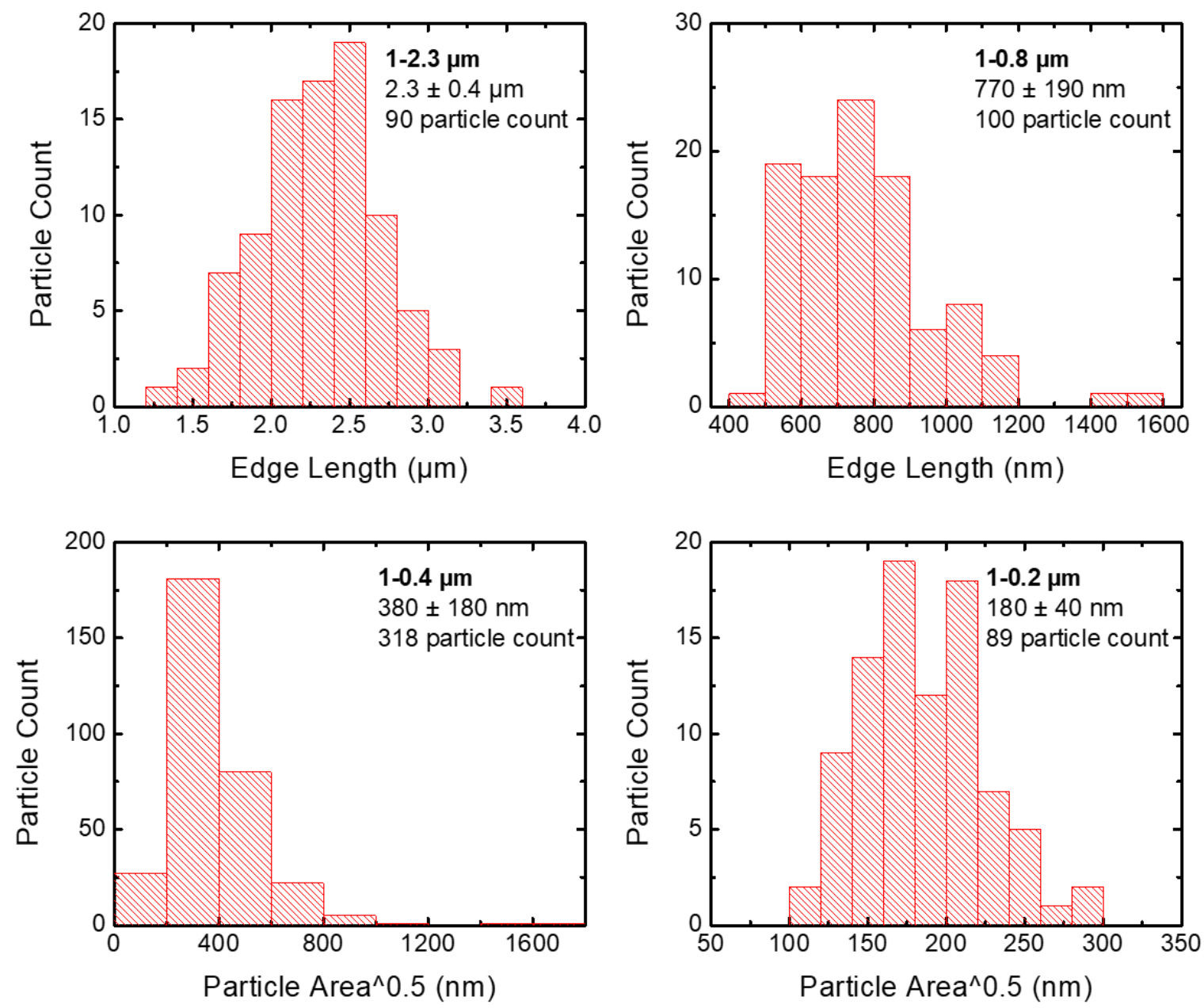

Figure S1. Histograms of particles from samples 1-2.3 $\mu \mathrm{m}, \mathbf{1 - 0 . 8} \mu \mathrm{m}, 1-0.4 \mu \mathrm{m}$, and 1$0.2 \mu \mathrm{m}$. 

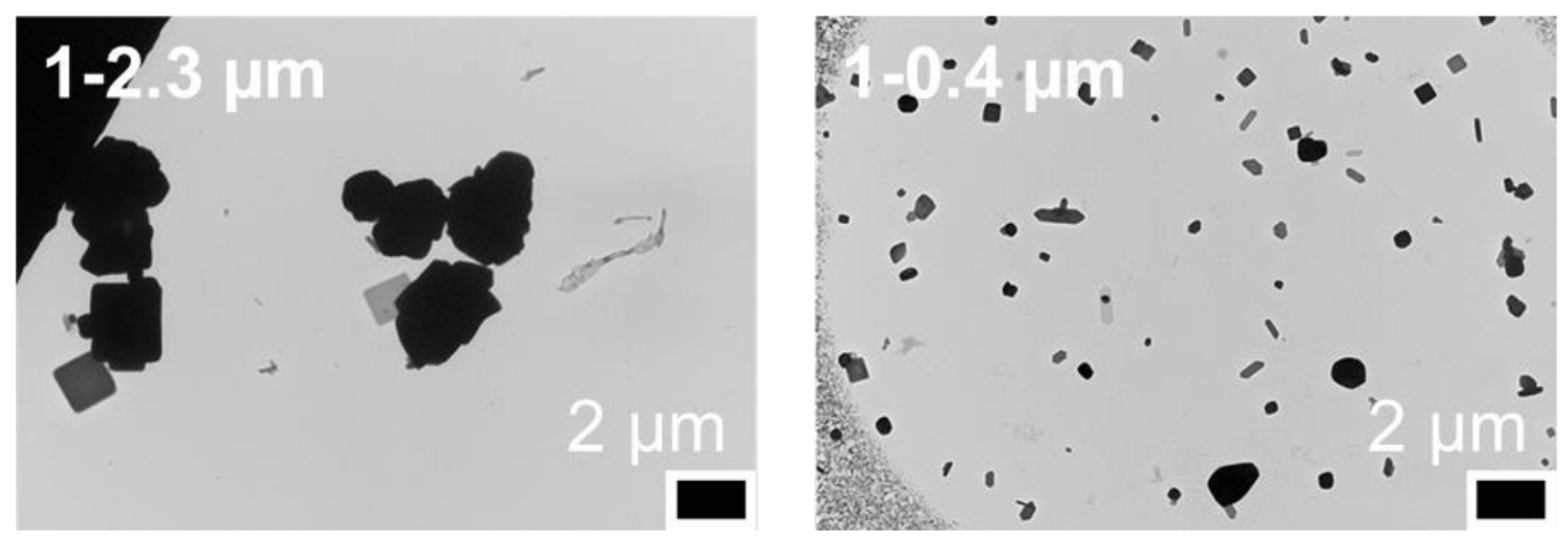

Figure S2. TEM images of particles from samples 1-2.3 $\mu \mathrm{m}$ and 1-0.4 $\boldsymbol{\mu m}$.

There are difficulties in imaging particles of DMMF, as particles aggregate while preparing the TEM sample. To avoid aggregation due to drying, an aliquot of the product can be set aside for TEM and a small amount of surfactant, 1-octyl-2-

pyrrolidone, can be added to the suspension. This post-synthetic treatment significantly increased the ability to image particles. 

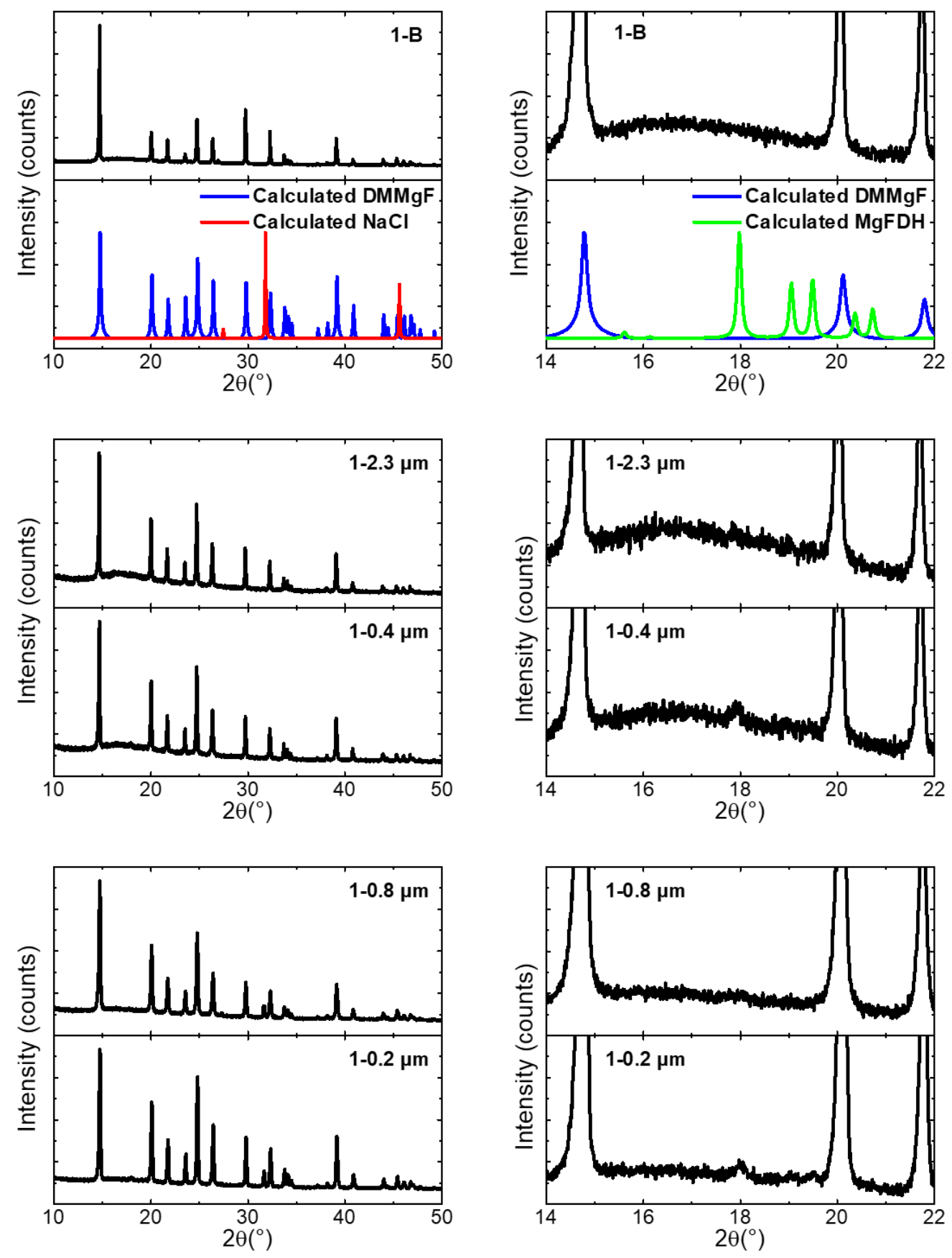

Figure S3. Room temperature PXRD patterns from samples 1-B, 1-2.3 $\mu \mathrm{m}, \mathbf{1 - 0 . 8} \mu \mathrm{m}, \mathbf{1 -}$ $0.4 \mu \mathrm{m}$, and 1-0.2 $\mu \mathrm{m}$ compared against the calculated pattern of DMMgF and MgFDH from Rossin et al. ${ }^{1}$ An additional weak reflection at $18^{\circ} 2 \theta$ in the DMMgF samples is attributed to $\mathrm{Mg}(\mathrm{HCOO})_{2}\left(\mathrm{H}_{2} \mathrm{O}\right)_{2}$, which is not uncommon for this family of materials. ${ }^{2,3}$ In the 1-0.8 $\mu \mathrm{m}$ and 1-0.2 $\mu \mathrm{m}$ diffractograms, additional reflections at $27.5^{\circ}, 31.8^{\circ}$, and $45.6^{\circ}$ due to an internal $\mathrm{NaCl}$ standard. 


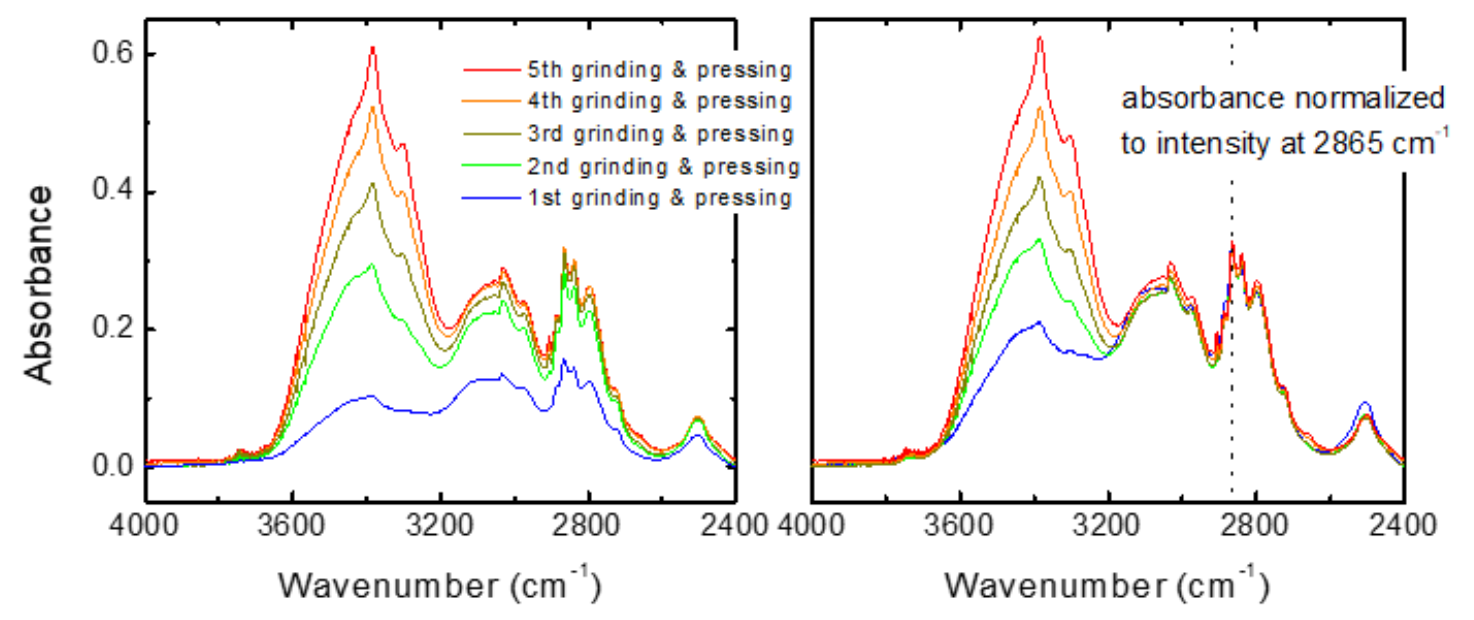

Figure S4. FTIR a crystal of DMMgF 1-B after consecutive $\mathrm{KBr}$ pellet grinding.

When preparing pressed pellets of sample ground in $\mathrm{KBr}$ for FTIR analysis, the ratio of peaks corresponding to magnesium formate dihydrate (MgFDH) compared to dimethylammonium magnesium formate (DMMgF) increased. Specifically, we see an increase in the peaks at $3300 \mathrm{~cm}^{-1}, 3380 \mathrm{~cm}^{-1}$, and $3440 \mathrm{~cm}^{-1}$, characteristic of MgFDH and a decrease in the peak at $2503 \mathrm{~cm}^{-1}$, characteristic of DMMgF. ${ }^{5}$

Dimethylammonium metal formate (DMMF) crystals are known to convert from metal formate dihydrate (MFDH) crystallites, ${ }^{3}$ showing that there can be an equilibrium between the two materials. From the crystallographic data of Rossin et al., ${ }^{1} \mathrm{MgFDH}$ is a more densely packed structure than $\mathrm{DMMgF}$, at $144 \AA^{3}$ per $\mathrm{Mg}$ atom and $217 \AA^{3}$ per $\mathrm{Mg}$ atom, respectively. Despite using dried $\mathrm{KBr}$, atmospheric water is still available and readily absorbed by the $\mathrm{KBr}$. The grinding process may be shifting the equilibrium between the DMMgF and MgFDH towards the denser MFDH. Additionally, breaking down the DMMgF crystals into smaller crystallites allows for better inclusion of the readily available water, and shorter escape path for the gaseous dimethylamine. 

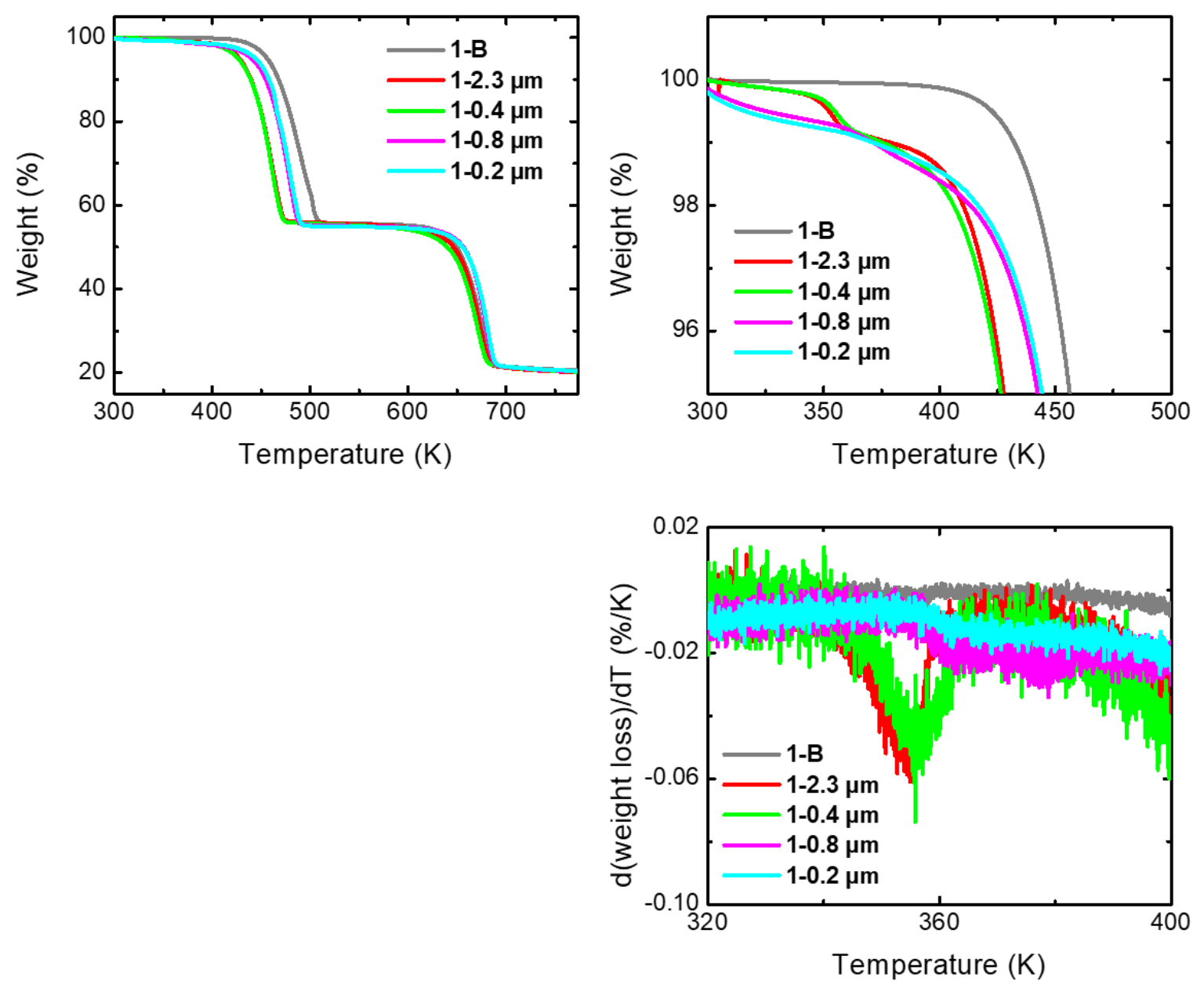

Figure S5. TGA curves from samples 1-B, 1-2.3 $\mu \mathrm{m}, \mathbf{1 - 0 . 8} \mu \mathrm{m}, \mathbf{1 - 0 . 4} \boldsymbol{\mu m}$, and 1-0.2 $\mu \mathrm{m}$ performed at a heating rate of $5 \mathrm{~K} / \mathrm{min}$ under a nitrogen purge flow of 10 $\mathrm{mL} / \mathrm{min}$. TGA can be used to quantify the extent of MgFDH impurity. Both $\left[\left(\mathrm{CH}_{3}\right)_{2} \mathrm{NH}_{2}\right] \mathrm{Mg}(\mathrm{HCOO})_{3}$ and $\mathrm{Mg}(\mathrm{HCOO})_{2}\left(\mathrm{H}_{2} \mathrm{O}\right)_{2}$ decompose to $\mathrm{Mg}(\mathrm{HCOO})_{2}$ upon thermal treatment below $520 \mathrm{~K} .{ }^{1,6}$ For $\left[\left(\mathrm{CH}_{3}\right)_{2} \mathrm{NH}_{2}\right] \mathrm{Mg}(\mathrm{HCOO})_{3}$, the loss of one amine and formic acid per formula unit occurs in the range of 430-500 $\mathrm{K}$; for $\mathrm{Mg}(\mathrm{HCOO})_{2}\left(\mathrm{H}_{2} \mathrm{O}\right)_{2}$, the loss of two water molecules occurs below 430 $\mathrm{K}$. These two events are often distinct, and the relative proportion of the two species present in a sample can be efficiently assessed. Both materials decompose down to $\mathrm{MgO}_{\mathrm{x}}$ beyond $700 \mathrm{~K} .{ }^{1}$ The samples contained less than $2.3 \%$ of $\mathrm{Mg}(\mathrm{HCOO})_{2}\left(\mathrm{H}_{2} \mathrm{O}\right)_{2}$. 


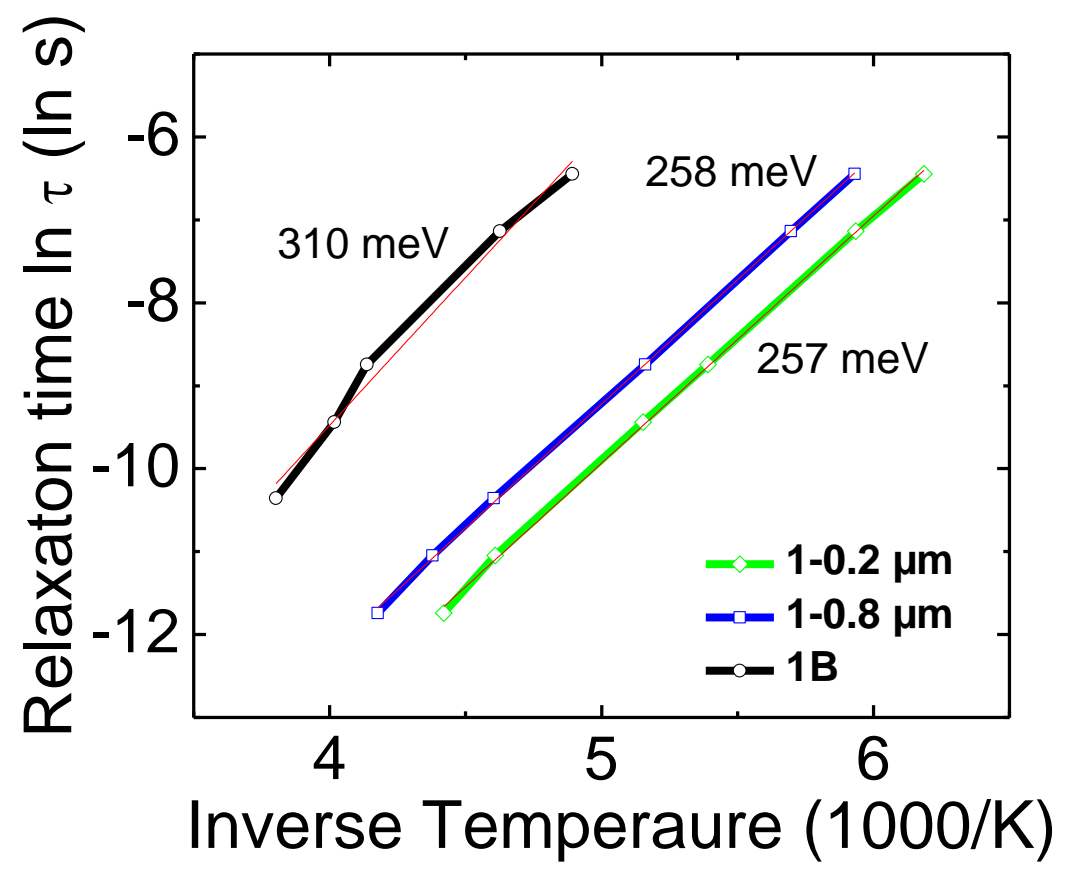

Figure S6. Inverse temperature dependence of the relaxation time of the samples 1-B, 1-0.8 $\mu \mathrm{m}$, and 1-0.2 $\mu \mathrm{m}$. The activation energy and the relaxation time (perexponential factor) were obtained from the slope and the intercept, respectively.

The data fit was as follows. The mean relaxation time $t$ was determined at each frequency $f$ of the imaginary dielectric permittivity measurement by

$$
2 \pi f=\frac{1}{\tau}
$$

The activation energy $E_{a}$ for the dipolar process was determined by

$$
\frac{\tau}{\tau_{0}}=e^{\frac{E_{a}}{k T}}
$$

where the temperature $T$ at which a maximum $\varepsilon$ " is reached for a given frequency, $k$ is the Boltzmann constant, and $\tau_{0}$ is the relaxation time. The data was fit using the linear form

$$
\ln (\tau)=\frac{E_{a}}{1000 k} \times \frac{1000}{T}+\ln \left(\tau_{0}\right)
$$

The activation energy of 1-B, 1-0.8 $\mu \mathrm{m}$, and $\mathbf{1 - 0 . 2} \mu \mathrm{m}$ is calculated to be $310 \pm 20 \mathrm{meV}$, $258 \pm 2 \mathrm{meV}, 257 \pm 3 \mathrm{meV}$, respectively. These values are in good agreement with the value of $273 \mathrm{meV}$ reported for $20 \mu \mathrm{m}$ crystallites of 1 reported in Šimènas et al. ${ }^{7}$ The relaxation time was found to be $50+80$ ps $\sim 50-30$ ps, $32 \pm 4$ ps, and $16 \pm 3$ ps in samples of 1-B, 1-0.8 $\boldsymbol{\mu m}$, and 1-0.2 $\mu \mathrm{m}$ respectively. The values for the $20 \mu \mathrm{m}$ ground crystallites of 1 are $17 \mathrm{ps}$ reported in Šimènas et al. ${ }^{7}$ 


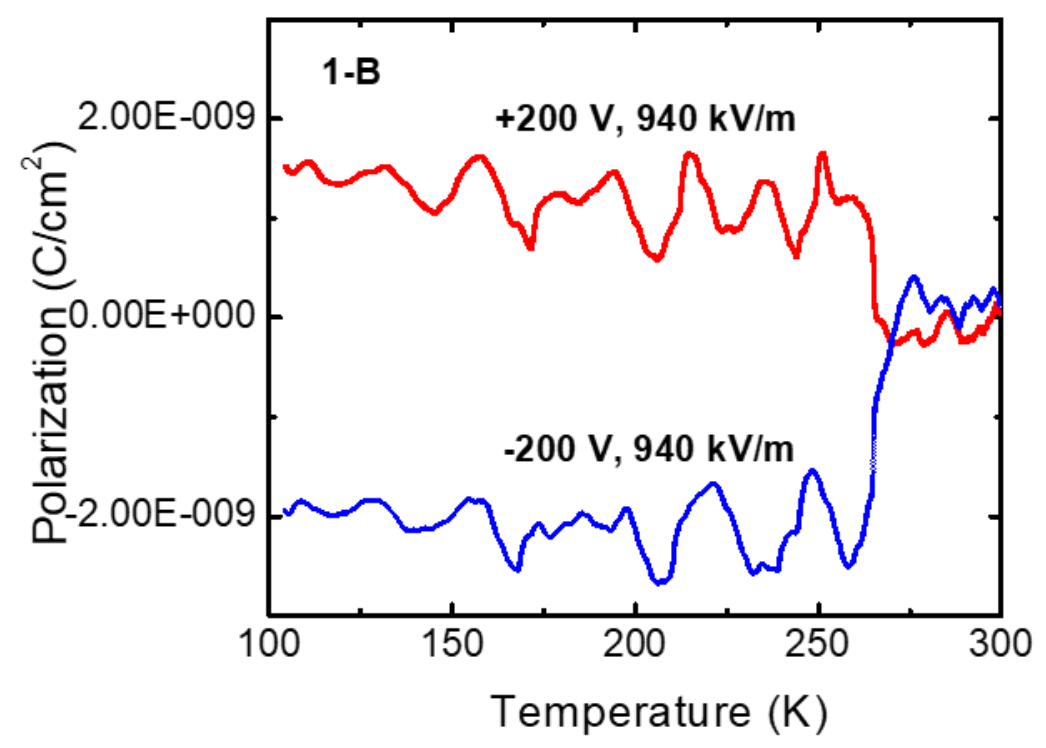

Figure S7. Polarization measurements for sample 1-B. 

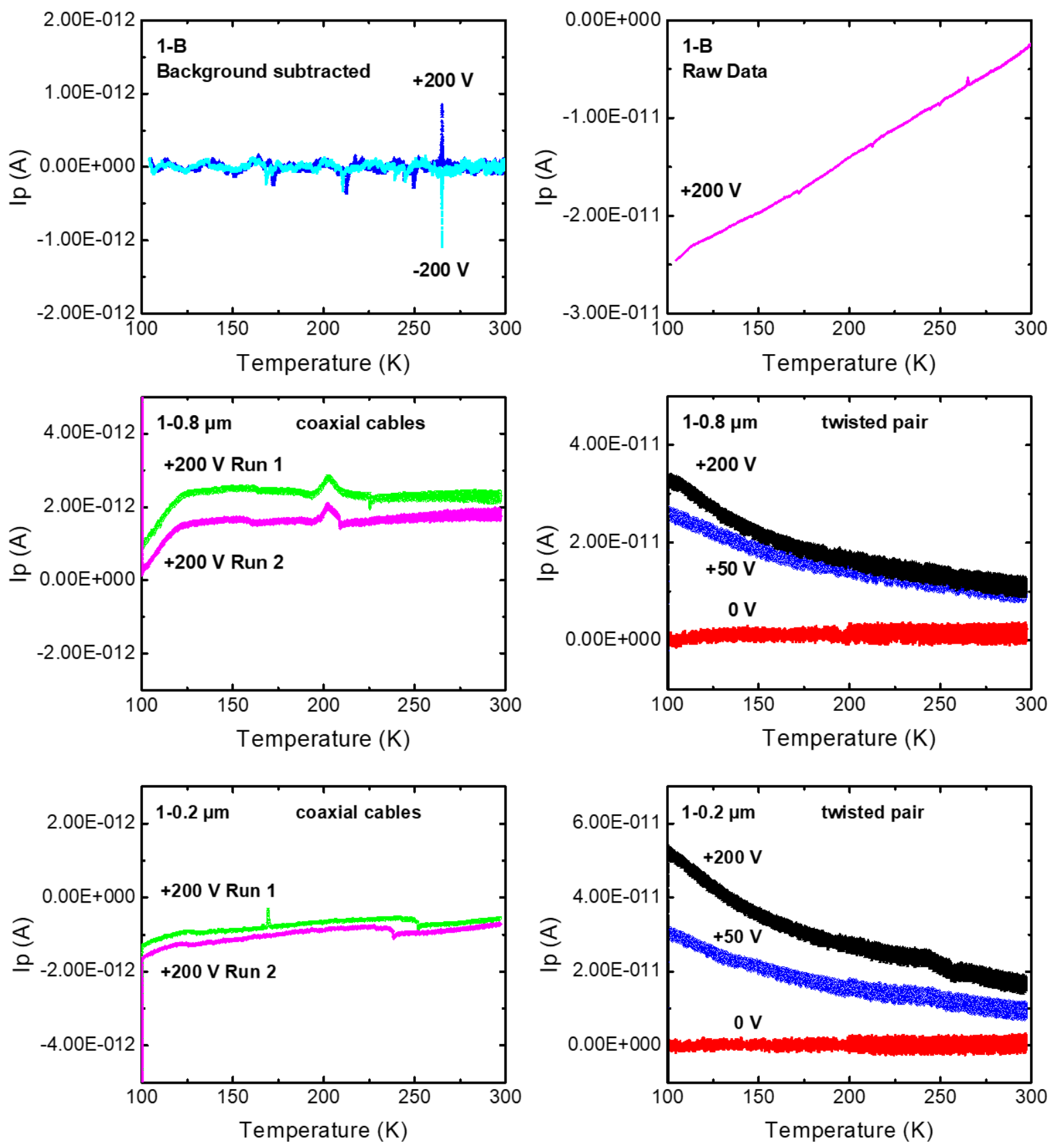

Figure S8. Pyroelectric current measurements for samples 1-B, 1-0.8 $\mu \mathrm{m}$, and 1-0.2 $\mu \mathrm{m}$. In the pyroelectric current data for $1-B$, a clear event occurs at $265 \mathrm{~K}$ under both positive polling and negative polling. For 1-0.8 $\mu \mathrm{m}$ and 1-0.2 $\mu \mathrm{m}$, the pyroelectric current was measured with differing wiring configurations, coaxial cables or twisted pairs, from the sample to the instrument. Under positive polling, no clear events are present in 1-0.8 $\mu \mathrm{m}$ and 1-0.2 $\mu \mathrm{m}$, although some I measurement artifacts are visible, which are either too broad or appear as dips rather than the peaks expected under positive polling. 
Table S1. Transition temperatures ${ }^{\mathrm{a}}$ and thermal hysteresis ${ }^{\mathrm{b}}$ as measured by DSC using a ramp rate of $2 \mathrm{~K} / \mathrm{min}$.

\begin{tabular}{cccc}
\hline Size & Sample & $T_{\mathrm{c}}(\mathrm{K})$ & Hysteresis $(\mathrm{K})$ \\
\hline Bulk & $\mathbf{1 - B}$ & 263.3 & 2.75 \\
$2.3 \pm 0.4 \mu \mathrm{m}$ & $\mathbf{1 - 2 . 3} \boldsymbol{\mu m}$ & $260.1 \pm 0.1$ & $6.9 \pm 0.4$ \\
$380 \pm 180 \mathrm{~nm}$ & $\mathbf{1 - 0 . 4} \boldsymbol{\mu m}$ & $251.5 \pm 0.6$ & $12.1 \pm 0.8$ \\
\hline
\end{tabular}

${ }^{a}$ The transition temperature, $T_{c}$, is defined as the halfway point between the endothermic and exothermic peak maxima.

${ }^{\mathrm{b}}$ The hysteresis is the difference between the endothermic and exothermic peak maxima. 


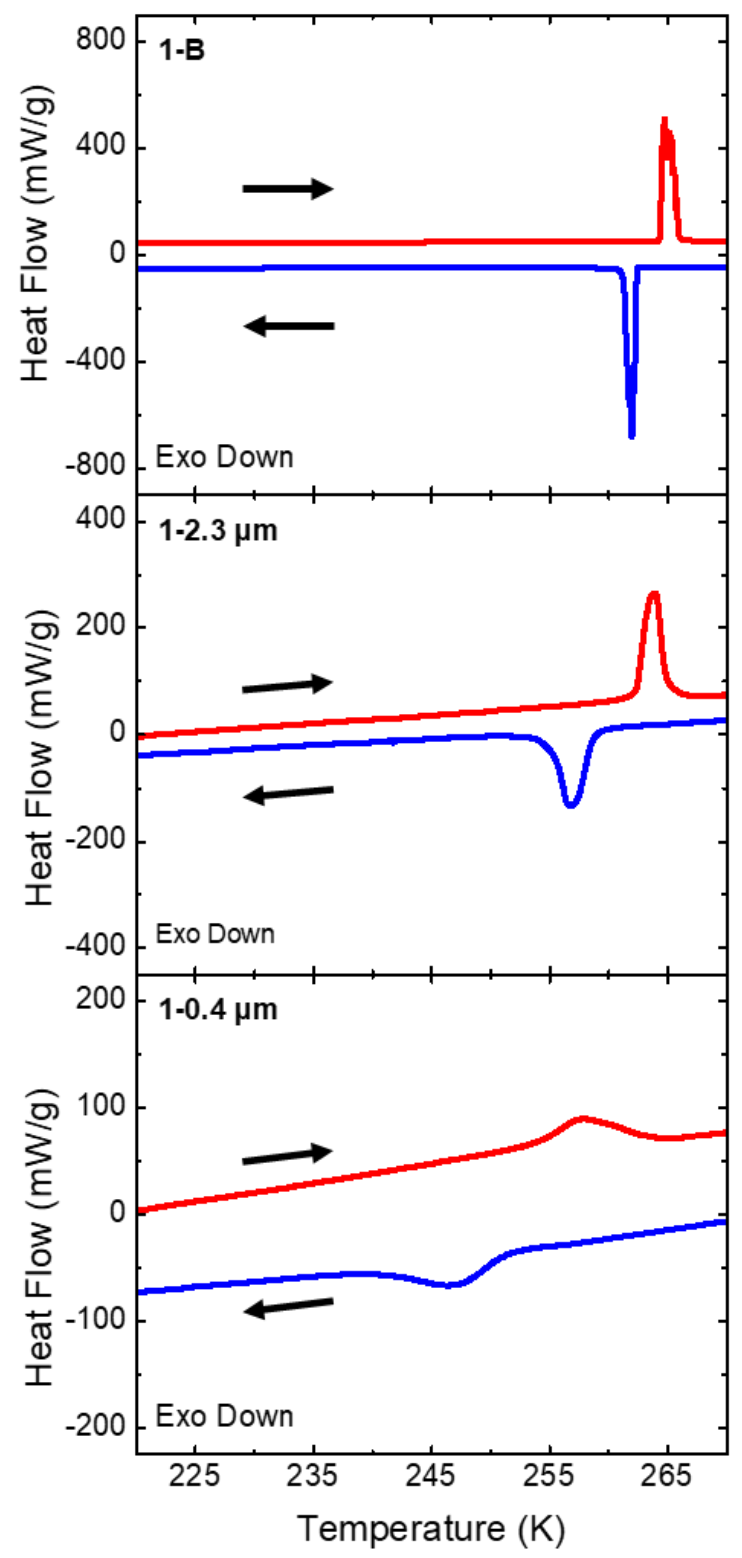

Figure S9. DSC curves from samples 1-B, 1-2.3 $\mu \mathrm{m}$, and 1-0.4 $\mu \mathrm{m}$ performed at a scan rate of $2 \mathrm{~K} / \mathrm{min}$. 


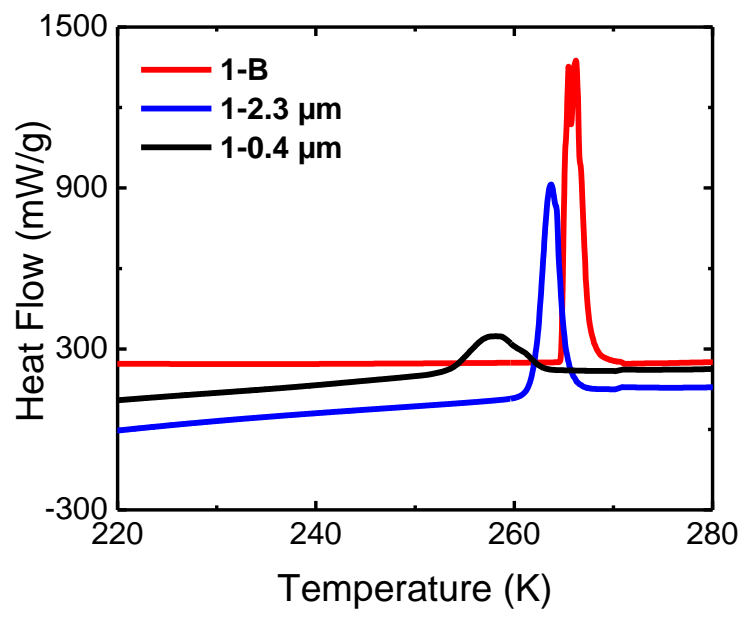

Figure S10. DSC curves from samples 1-B, 1-2.3 $\mu \mathrm{m}$, and 1-0.4 $\mu \mathrm{m}$ performed at a scan rate of $10 \mathrm{~K} / \mathrm{min}$.

Table S2. Assignment of prominent VT-PXRD peaks of 1-2.3 $\mu \mathrm{m}$ and 1-0.4 $\mu \mathrm{m}$.

\begin{tabular}{cccc}
\hline HTP Assignment & $\begin{array}{c}\text { HTP Reflections } \\
\left({ }^{\circ}\right)\end{array}$ & LTP Assignment & $\begin{array}{c}\text { LTP Reflections } \\
\left({ }^{\circ}\right)\end{array}$ \\
\hline$(-222)$ & 26.4 & $(220)$ & 26.4 \\
& & $(-402)$ & 26.9 \\
$(024)$ & 29.8 & $(400)$ & 29.5 \\
& & $(-222)$ & 30.1 \\
$(-126)$ & 32.3 & $(311)$ & 32.0 \\
& & $(022)$ & 32.4 \\
$(-231)$ & 33.8 & $(-313)$ & 32.9 \\
\hline
\end{tabular}

Assignments made from consulting Rossin et al., ${ }^{1}$ Pato-Doldán et al., ${ }^{8}$ and Sánchez-Andújar et al. ${ }^{9}$ 


\section{References}

1. Rossin, A.; lenco, A.; Costantino, F.; Montini, T.; Di Credico, B.; Caporali, M.; Gonsalvi, L.; Fornasiero, P.; Peruzzini, M. Phase transitions and $\mathrm{CO}_{2}$ adsorption properties of polymeric magnesium formate. Cryst. Growth Des. 2008, 8, 3302-3308. 2. Averback, C. M. Controlling phase behavior of coordination polymer networks and two-dimensional organic-inorganic compounds. Ph. D. Dissertation, University of Florida, Gainesville, FL, 2017.

3. Wang, X. Y.; Gan, L.; Zhang, S. W.; Gao, S. Perovskite-like metal formates with weak ferromagnetism and as precursors to amorphous materials. Inorg. Chem. 2004, 43, 4615-4625.

4. Stoilova, D.; Koleva, V. IR study of solid phases formed in the $\mathrm{Mg}(\mathrm{HCOO})_{2-}$ $\mathrm{Cu}(\mathrm{HCOO})_{2}-\mathrm{H}_{2} \mathrm{O}$ system. J. Mol. Struct. 2000, 553, 131-139.

5. $\quad$ Szymborska-Malek, K.; Trzebiatowska-Gusowska, M.; Mączka, M.; Gągor, A. Temperature-dependent IR and Raman studies of metal-organic frameworks $\left[\left(\mathrm{CH}_{3}\right)_{2} \mathrm{NH}_{2}\right]\left[\mathrm{M}(\mathrm{HCOO})_{3}\right], \mathrm{M}=\mathrm{Mg}$ and Cd. Spectrochim. Acta, Part A 2016, 159, 35-41. 6. Nagabhushana, G. P.; Shivaramaiah, R.; Navrotsky, A. Thermochemistry of multiferroic organic-inorganic hybrid perovskites $\left[\left(\mathrm{CH}_{3}\right)_{2} \mathrm{NH}_{2}\right]\left[\mathrm{M}(\mathrm{HCOO})_{3}\right](\mathrm{M}=\mathrm{Mn}, \mathrm{Co}$, $\mathrm{Ni}$, and Zn). J. Am. Chem. Soc. 2015, 137, 10351-10356.

7. Šimènas, M.; Balčiūnas, S.; Gonzalez-Nelson, A. Kinka, M.; Ptak, M.; van der Veen, M. A.; Mączka, M.; Banys, J. Preparation and Dielectric Characterization of P(VDF-TrFE) Copolymer-Based Composites Containing Metal-Formate Frameworks. J. Phys. Chem. C 2019, 123, 16380-16387.

8. Pato-Doldán, B.; Sánchez-Andújar, M.; Gómez-Aguirre, L. C.; Yáñez-Vilar, S.; López-Beceiro, J.; Gracia-Fernández, C.; Haghighirad, A. A.; Ritter, F.; CastroGarcía, S.; Señarís-Rodríguez, M. A. Near room temperature dielectric transition in the perovskite formate framework $\left[\left(\mathrm{CH}_{3}\right)_{2} \mathrm{NH}_{2}\right]\left[\mathrm{Mg}(\mathrm{HCOO})_{3}\right]$. Phys. Chem. Chem. Phys. 2012, 14, 8498-8501.

9. $\quad$ Sánchez-Andújar, M.; Gómez-Aguirre, L. C.; Pato-Doldán, B.; Yáñez-Vilar, S.; Artiaga, R.; Llamas-Saiz, A. L.; Manna, R. S.; Schnelle, F.; Lang, M.; Ritter, F.; Haghighirad, A. A.; Señarís-Rodríguez, M. A. First-order structural transition in the multiferroic perovskite-like formate $\left[\left(\mathrm{CH}_{3}\right)_{2} \mathrm{NH}_{2}\right]\left[\mathrm{Mn}(\mathrm{HCOO})_{3}\right]$. CrystEngComm 2014, 16 , 3558-3566. 